\title{
Why Banks Should Keep Secrets
}

\author{
Todd R. Kaplan* \\ Department of Economics \\ University of Exeter \\ Exeter EX4 4PU, UK
}

August 23, 2000

\begin{abstract}
We show that it is sometimes efficient for a bank to commit to a policy that keeps information about its risky assets private. Our model, based upon Diamond-Dybvig [1983], has the feature that banks acquire information about their risky assets before depositors acquire it. Banks have the option of using contracts where the middle-period return on deposits is contingent on this information, but by doing so they must also reveal the information. We derive the conditions on depositors' preferences and bankers' technology for which banks would prefer to keep information secret even though they must then use non-contingent deposit contracts.

Keywords: deposit contracts, interim information

JEL Classification: G21; D8
\end{abstract}

\section{Introduction}

In the 1980's, poor credit risks caused the failure of many Savings \& Loans. In response to these failures, the U.S. government enacted legislation devised to prevent such crises. The Financial Institutions Reform, Recovery, and Enforcement Act of 1989 and the Federal Deposit Insurance

*E-mail: todd@toddkaplan.com. I would like to thank an anonymous referee, Sudipto Bhattacharya, Ed Green, Chandra Kanodia, Andy McLennan, Arijit Mukherji, Bradley Ruffle, Neil Wallace, Warren Weber, and especially Nobu Kiyotaki for useful comments and suggestions. This paper builds on Chapter 1 of my University of Minnesota dissertation. I also thank the Monaster Center for Economics Research for financial support. 
Corporation Improvement Act of 1991 made changes to banking laws designed to reduce moralhazard problems and prevent losses from federal insurance. ${ }^{1}$

Part of these laws limit the ability of a bank to keep information private by creating a minimum capital requirement, imposing a new examination standard for bank assets, and implementing a risk-based insurance scheme. A minimum capital requirement entails accurate measurements of a bank's capital. Likewise, a risk-based insurance scheme is based on both a bank's capital and the riskiness of a bank's investments. These changes require altering both the examination standard and accounting methods of bank assets. Furthermore, they increase revelation about a bank's assets as do other moves to have banks mark loans at market value rather than book value. ${ }^{2}$ This leads us to the main question of the paper: Could this increase of information about a bank's assets have unintended adverse effects?

This question of whether an increase in information can lead to a decrease in welfare appears in other contexts. ${ }^{3}$ Hirshleifer [1971] shows that an increase of information may hurt efficiency in an exchange economy (the breadth of examples was recently expanded by Schlee [2000]). Verrecchia [1982] then shows such may be the case in insurance markets. ${ }^{4}$ Eckwert and Zilcha [2000] study when additional information may hurt in a production economy. In a different type of setting, Maskin and Tirole [1990, 1992] analyze the role of an informed principal in a principal-agent model and find that when values are private, the principal does strictly better by not revealing his information. In another context, Kaplan and Zamir [2000] show that in an auction a seller can exploit this "information property" by giving buyers additional information about other buyers' valuations making the outcome of the auction worse for the buyers and better for the seller with an overall welfare loss.

${ }^{1}$ FIRREA; P.L. 101-73, 103 STAT. 183. FDICIA; P.L. 102-242, 105 STAT. 2236. There was also the Crime Control Act of 1990 (P.L. 100-86, 101 STAT. 552) and the Competitive Equality Banking Act of 1987 (P.L. 101-647, 104 STAT. 4789)

${ }^{2}$ Marking loans at book value rather than market value hides the real value of fixed-rate loans by ignoring changes to market interest rates.

${ }^{3}$ Townsend [1988] answers the related question of whether decreasing the costs of acquiring information may hurt welfare. This is a smoothed version of the result that decreasing the costs of acquiring information from infinite to zero hurts welfare.

${ }^{4}$ We can understand this result by looking at recent developments of genetic tests that determine a woman's predisposition to breast cancer. These tests provide benefits such as more frequent screenings for susceptible women and preemptive surgery; however, if insurance companies could screen applicants with such tests, genetically predisposed women would not be able to obtain insurance. Overall, society may be worse off than not having such tests. 
To ask this question in a banking context, we use a version of the Diamond-Dybig model [1983] with a risky investment where the bank and depositors are asymmetrically informed about the return on investment in the middle period. Similar environments have been analyzed in the literature. Gorton [1985] presents a model in which banks would like to communicate their superior information about their risky investments to their depositors, but are unable to do so costlessly; instead, a bank allows a run to occur when the return is low relative to the depositors' outside option and suspends payment when it is high. Jacklin and Bhattacharya [1988] have a portion of depositors receive an interim, noisy signal about a bank's investments and compare demand-deposits to equity trading. Alonso [1996] uses the Jacklin and Bhattacharya framework to show that although a bank can write a run-proof contract it is not always optimal to do so. Hazlett [1997] compares different deposit insurance schemes with risky investments.

Our model, while similar to the aforementioned models, is tailored toward the question we wish to answer. As in Diamond and Dybvig, we have three periods in which initially depositors don't know whether they derive relatively high utility from the middle or the last period. Depositors who derive utility in the middle period are impatient, while depositors who enjoy both middle and last periods are patient. Each depositor's type is private information and discovered only in the middle period.

The bankers have access to a constant-returns-to-scale investment technology. This technology offers a safe middle-period return and an uncertain last-period return. A key assumption is that in the middle period, only the bankers learn the risky last-period return. In the initial period, the banks competitively offer deposit contracts that specify payments to depositors. A bank also has the ability to make the middle-period payments (not just the last-period payments) contingent upon the bank's information. However, a bank writing such contingent contracts implicitly reveals its information; depositors cannot be ignorant of the same information on which their received payments are based. ${ }^{5}$ The only way for a bank to keep its information private is to write contracts with a non-contingent middle-period payment. Thus, we permit a bank to choose whether to reveal its information and offer contingent contracts or not to reveal its information and offer non-contingent contracts (a third option of revealing its information and offering a non-contingent contract is weakly dominated by the second). This dilemma of the bank allows us to answer our question in the following line of reasoning. If a bank always chooses to reveal its information with a contingent contract, then forcing a bank to reveal its information

\footnotetext{
${ }^{5}$ The assumption of non-contingent contracts present in many models avoids this potential conflict.
} 
will have no effect. However, if there is a case when a bank chooses to offer a non-contingent contract and doing so leads to a strictly better outcome, then the same contract with information revealed will result that when the return is low, the patient depositors would claim to be impatient depositors. Thereby, the bank would be forced to offer the inferior, contingent contract. Thus, forcing a bank to disclose information will have an adverse effect.

We find such a case by first finding the technological conditions under which the patient depositors' incentive constraints will bind. Then, by showing that if these constraints are indeed binding and the depositors are moderately risk averse (the degree of relative risk aversion is between one and two), then the banks will conceal their private information by offering noncontingent contracts.

The format of this paper is as follows. Section 2 describes the model. The equilibrium concept is defined and the equivalent Social Planner's problem is derived in Section 3. Results are analyzed in Section 4 and the conclusions are discussed in Section 5.

\section{Model}

The banking environment, similar to the one in Diamond-Dybvig [1983], is described in this section.

\section{Time periods, goods, depositors and preferences}

There are three time periods, 0,1 , and 2 (referred to as initial, middle, and last), and one good for each period. Let $c_{t}$ denote an allocation of time $t$ good and $c=\left(c_{0}, c_{1}, c_{2}\right)$ denote an allocation bundle. There is a continuum with measure one of ex-ante identical depositors. Each depositor is endowed with one unit of time 0 good. At time 1, depositors privately discover whether they are either impatient $(i)$ or patient $(p)$. Impatient depositors enjoy only the time $1 \operatorname{good}\left(u_{i}(c)=u\left(c_{1}\right)\right)$, while the patient depositors enjoy both the time 1 good and the time $2 \operatorname{good}\left(u_{p}(c)=u\left(\rho \cdot c_{1}+c_{2}\right)\right)$. There is a preference parameter $\rho$ that represents a patient depositor's preference between the time 1 good and the time 2 good. ${ }^{6}$ The utility function, $u$, is twice differentiable, increasing and strictly concave. Each depositor has an equal chance of

\footnotetext{
${ }^{6}$ This preference parameter (if greater than one) can be thought of as an outside investment opportunity available at time 1. Such an outside investment is reminiscent of Gorton [1985] where depositors may prefer it to the bank's investment technology; however, in our model the outside investment is always inferior.
} 
being either type and there is no aggregate uncertainty in regards to depositor types.

\section{Banks and their technology}

In addition to the depositors, there is a finite number of banks, $N$, strictly larger than one. For simplicity, each bank derives utility from only the time 2 good. Also, each bank has no endowment, but has access to a constant-returns-to-scale investment technology. This technology is risky and converts a time 0 good into either one unit of time 1 good or an uncertain amount, $R_{s}$, of time 2 good that depends upon the state of world, $s$. The technology is described by

$$
\left\{\left(z_{0}, z_{1}, z_{2}\right) \mid z_{1}+\frac{z_{2}}{R_{s}} \leq-z_{0}\right\}
$$

A bank can invest $z_{0}$ units of time 0 good, where $z_{0} \leq 0$, to obtain $z_{1}$ time 1 goods and $z_{2}$ time 2 goods, where the choice of $z_{1}$ and $z_{2}$ is made at time 1 . There are two states of the world: high $(\mathrm{s}=\mathrm{h})$ and low $(\mathrm{s}=\mathrm{l})$. The probability of a high state is $\mu$, while the probability of a low state is $1-\mu$. Each bank learns the state at time 1. The state is the private information of the banks and is the same for all banks (that is, the returns on investments are perfectly correlated). The technology is such that $R_{h}>R_{l}>\rho$.

\section{Timing}

Decisions are made during time periods 0 and 1 . During time period 0 , each bank, simultaneously with the other banks, offers a contract, that is, an agreement between a depositor and a bank where the depositor gives up one unit of time 0 good in exchange for a certain amount of either time 1 goods or time 2 goods. A contract is described more explicitly below in the contract section. Each depositor sees the banks' offers and then selects, simultaneously with the other depositors, a contract by choosing a bank.

After time 1, all depositors and banks learn the decisions that were made during period 0. During time period 1, nature determines the state of the investment, the depositors' types and the order the depositors play in period 1 . There is an equal chance of any queuing order for the depositors. Each depositor learns his type (patient or impatient) and each bank learns the state of the world (high or low). All depositors line up at their bank in the order that was determined by nature and are sequentially served by their chosen bank (as described below in the sequential service section). When served, a depositor must decide either to withdraw at time 1 or at time 2. At time 2, the depositors who decided to wait make withdrawals. In summary, depositors 
make two decisions (choice of bank and timing of withdrawals) while banks make one (choice of contract, which is discussed in the following section).

\section{Contract}

At time 0 , each bank offers depositors a contract in exchange for one unit of time 0 good. This contract is of the form $\left\{x_{l}, y_{l}(f), x_{h}, y_{h}(f), F\right\}$. In each contract, $x_{s}$ corresponds to the amount of time 1 good that will be given to someone withdrawing at time 1 when less than fraction $F$ of depositors have already withdrawn and the state is $s=l, h$, while the function $y_{s}(f)$ corresponds to the amount of time 2 good that will be given to someone withdrawing at time 2 if the state is $s$ and $f$ depositors withdrew at time 1 .

A contract is feasible if it is technologically possible for both possible states of the investment, that is,

$$
y_{s}(f)(1-f) \leq R_{s}\left(1-f \cdot x_{s}\right)
$$

for all $f$ less than $F$ and $s=l, h$.

This contract is enforceable. A bank must pay the amounts specified in its contract. If a payment is state dependent, the bank offering that payment is obligated to pay the amount corresponding to the actual state. Thus, after the realization of the state at time 1 , a bank must liquidate a sufficient portion of its investment in order to meet potential time 1 demands $F \cdot x_{s}$.

\section{Sequential Service}

During time period 1 , depositors are sequentially served in the following manner. At the front of the line, there is a teller window. There is a sign with the amount that the bank is paying depositors, $x_{s}$, posted above the window. Once at the front of the line a depositor has to decide either to advance to the window and withdraw or to leave the line and come back at time 2 . If depositors of measure $F$ have chosen to withdraw, the bank must immediately change the sign to read zero.

Depositors are myopic; their poor vision prevents them from seeing how many depositors stand before them or after them in line. However, if the posted amount is nonzero, a depositor can deduce that the number of depositors who already withdrew is less than the cutoff, $F$. If the payoff is zero and the contract offered a nonzero initial payoff $\left(x_{s}>0\right)$, a depositor can deduce that the number of depositors who already withdrew is greater than the cutoff. If a depositor 
chooses to be served at the window, he can not return at time 2. At time 2, all depositors who have not already withdrawn are served simultaneously. ${ }^{7}$

The sequential-service constraint presented here is different from the constraint in DiamondDybvig [1983] in that all depositors line up at the bank (as opposed to only early withdrawers). It more closely resembles the sequential-service constraint in Wallace [1988, 1990], but differs in that only the early withdrawers go to the window. That way, the depositors are able to gain information about the state of the bank, while the bank learns nothing about the nonwithdrawing depositors.

\section{Information Transmission}

It is costless for a bank to transmit the state of its investments. However, a feature of our model is that a bank in general would not like to release information. ${ }^{8}$ There is still a dilemma since if a bank wishes to pay impatient depositors a contingent middle-period payment, by our sequentialservice constraint it must also transmit the state of its investment with this payment. The only way to hide information is for the bank to make a non-contingent middle-period contract. Hence, we coin the term "revealing contract" for a contingent contract and "non-revealing contract" for a non-contingent contract.

\footnotetext{
${ }^{7}$ The results of this paper would not change if depositors sequentially lined up at time 2 or if the depositors who decide to withdraw at time 1 could receive both time 1 and time 2 goods.

${ }^{8}$ In general in mechanism design, the designer would not like to release information before eliciting information from the agents. The withholding of information leads to extra slack in the incentive constraints (which must be satisfied for each state individually rather than using the expectation over states, see Tirole [1990] for further explanation). We should note that our structure is a little more rigid due to the sequential-service constraint. This prevents a bank (the designer) from collecting information (whether a depositor is impatient or not) from all the depositors (agents) before making allocation decisions. It also forces a bank to reveal these allocation decisions before finishing the collection of information. Still, in general a bank would like to reveal as little information as possible. The one exception is contrary to our assumption if $\rho>R_{l}$, then the bank (designer) would want the patient depositor to take the middle-period payment in the case of a low return (similar to Gorton [1985]). The bank can do this only if the patient depositors show up to the bank and thus would like to communicate the state. Normally, the payments of the impatient depositors would be contingent on this information, thus revealing this information. However, if it was optimal not to make the payments contingent (such as if relative risk-aversion where equal to one), then it would be costly to communicate the state in this manner and thus would prefer a prior announcement.
} 


\section{Differences from Diamond-Dybvig}

There are three major differences between our model and Diamond-Dybvig's model. First, in our model the investment technology has risk. Second, the preferences of the patient depositors are more generally defined with parameter $\rho$ (Diamond-Dybvig have $\rho=1$ ). Finally, the banks have the ability to suspend payments. This allows a bank to costlessly prevent bank runs which allows us to focus the paper on the risk-sharing contracts derived from the model. ${ }^{9}$

\section{Equilibrium}

\section{Equilibrium Concept}

The banks' selection of contracts, the depositors' choices of banks, and depositors' withdrawal dates, form an equilibrium of the game if

- All contracts, $\left\{x_{s}, y_{s}(f), F\right\}$, are feasible.

- Each bank chooses a contract that maximizes its expected profit $E\left[R_{s}\left(1-f \cdot x_{s}\right)-(1-\right.$ $f) \cdot y_{s}(f)$ ] given the other banks' contracts, the depositors' choices of banks, and the depositors' withdrawal dates.

- Each depositor's choice of bank maximizes his expected utility given the other depositors' choices of banks and the depositors' withdrawal dates for all possible contracts the banks might offer.

- Each depositor's withdrawal date maximizes his expected utility given the depositors' choices of banks for all possible contracts and all possible time 1 withdrawal offers generated by those contracts and whether he is patient or impatient.

\footnotetext{
${ }^{9}$ The costless prevention of bank runs is due to the absence of aggregate uncertainty in regards to the number of impatient depositors.
} 


\section{Equivalent Social Planner Problem}

Due to conditions leading to competition similar to Bertrand, ${ }^{10}$ the contract accepted by the depositors in equilibrium is equivalent to the contract that the Social Planner chooses when maximizing the depositors' expected utility subject to both incentive constraints and a balanced budget for all states of nature. We use the following lemma to reduce the Social Planner's Problem to the more manageable formulation listed after the lemma.

Lemma 1. The solution to the Social Planner's Problem separates impatient from patient depositors and furthermore allocates only time 1 goods to impatient depositors and time 2 goods to patient depositors.

We should note that Lemma 1 allows us to ignore the good of a particular time period being given to more than one type of depositor as in pooling or partial pooling contracts as well as ignore more than one time period good being given to a depositor. We should further note that the Social Planner's Problem, presented below, has a unique solution. ${ }^{11}$

Social Planner's Problem (reduced) is selecting a contract $\left\{x_{s}, y_{s}(f), F\right\}$ such that $F=.5$ and $y_{s}(f)=y_{s}$ for all $f \geq .5$ and $y_{s}(f)=\frac{1-f \cdot x_{s}}{1-f}$ otherwise; and $\left\{x_{l}, y_{l}, x_{h}, y_{h}\right\}$ solve

$$
\max _{x_{l}, y_{l}, x_{h}, y_{h}}(1-\mu)\left[u\left(x_{l}\right)+u\left(y_{l}\right)\right]+\mu\left[u\left(x_{h}\right)+u\left(y_{h}\right)\right]
$$

subject to feasibility and either revealing incentive-compatibility or non-revealing incentive-compatibility constraints (of the patient depositors).

- feasibility

$$
\begin{gathered}
x_{l}, y_{l}, x_{h}, y_{h} \geq 0 \\
y_{s}=R_{s}\left(2-x_{s}\right) \text { for } s=l, h
\end{gathered}
$$

- revealing incentive constraints

$$
u\left(\rho \cdot x_{s}\right) \leq u\left(y_{s}\right) \text { for } s=l, h
$$

\footnotetext{
${ }^{10}$ There may exist additional equilibria where a bank can make positive profits in equilibrium. This was first mentioned by Adao and Temzelides [1998], who eliminate these additional equilibria by restricting the depositors to pure strategies and invoking forward induction arguments. Kaplan [1996] suggests another possibility that assumes each bank has a monopoly over an $\epsilon$ number of depositors and taking the limit as $\epsilon \rightarrow 0$.

${ }^{11}$ The maximand is a linear combination of concave functions and is therefore also concave. The feasibility constraint is linear so the set of points that satisfy it is convex. Therefore, the solution is unique.
} 
- non-revealing incentive constraints

$$
\begin{gathered}
u\left(\rho \cdot x_{l}\right) \leq(1-\mu) \cdot u\left(y_{l}\right)+\mu \cdot u\left(y_{h}\right) \\
x_{l}=x_{h}
\end{gathered}
$$

\section{Results}

We begin by looking at the full-information allocation as a possible solution to the Social Planner's problem. ${ }^{12}$ This allocation implements the first-best allocation. We need to examine this solution to determine if it violates the incentive-compatibility constraints. If it doesn't, then the first-best allocation is a solution to the model. If it does, then the Social Planner has the choice of using either a second-best contingent contract or a non-revealing non-contingent contract. The existence of parameters resulting in the later would support the banks' perogative to keep secrets.

\section{Full-Information Solution}

The solution $\left(x_{l}^{*}, y_{l}^{*}, x_{h}^{*}, y_{h}^{*}\right)$ to the full-information problem (the Social Planner's problem without incentive-compatibility constraints) has the following properties.

Property 1. The solution is independent of the probability of the high state of investment $\mu$.

This mainly follows since from the Social Planner's inability to risk-share between the high and low states due to the budget (feasibility) constraints.

Property 2. The patient depositor receives more in the high state than the low state, that is, $y_{h}^{*}>y_{l}^{*}$.

It is reassuring that the patient depositors receive more in the high state of the world, because only they can reap the rewards of the higher technological output.

Property 3. In each state, the patient depositor receives more than the impatient depositor, that is, $y_{l}^{*}>x_{l}^{*}$ and $y_{h}^{*}>x_{h}^{*}$.

This result is consistent with Diamond-Dybvig and logical here since it is less costly to provide a good to the patient depositor. We now see that although the state is known to the

\footnotetext{
${ }^{12}$ In the full-information, the Social Planner learns the types of the depositors in the middle period.
} 
bank in the middle period, the impatient depositors gain from the higher state only if they are sufficiently risk averse.

Assumption 1. Relative Risk Aversion is greater than 1. $\left(-\frac{u^{\prime \prime}(x) x}{u^{\prime}(x)}>1\right)$ for all $x>0$.

Assumption 2. Relative Risk Aversion is less than 1. $\left(-\frac{u^{\prime \prime}(x) x}{u^{\prime}(x)}<1\right)$ for all $x>0$.

As we now see, Assumption 1, which also appears in Diamond-Dybvig, causes banks to be risk-sharing institutions.

Property 4. Under Assumption 1, the impatient depositor receives more in the high state than in the low state, that is, $x_{h}^{*}>x_{l}^{*}>1$. Under Assumption 2, the impatient depositor receives less in the high state than in the low state, that is, $x_{h}^{*}<x_{l}^{*}<1$.

We see that only when there is sufficient risk-aversion, as in Assumption 1 (which also appears in Diamond-Dybvig), are banks risk-sharing institutions. This result agrees with the results of Diamond-Dybvig and occurs since, unlike the risk-sharing in Rothschild-Stiglitz [1976], transfer between the two types of depositors does not occur at a one-to-one ratio (impatient depositors are at a disadvantage). Therefore, there is a trade off between risk-sharing and the total surplus to be shared. When risk-aversion is high, the risk-sharing aspects dominate. When risk-aversion is low, the total surplus aspects dominate.

Theorem 1. If either Assumption 2 holds or the patient depositor's discount parameter, $\rho$, is less than one or sufficiently close to one, the contract that solves the Social Planner problem is equivalent to the full-information contract.

Proof: If Assumption 2 holds, then Property 4 implies that $x_{h}^{*}<x_{l}^{*}<1$. This in turn implies that $y_{s}^{*}>R_{s} \cdot x_{s}^{*}$. Since $\rho<R_{s}$, it must also be that $y_{s}^{*}>\rho \cdot x_{s}^{*}$. We also see that even if Assumption 2 does not hold, then Property 3 states that $y_{s}^{*}>x_{s}^{*}$. Thus, if $\rho$ is sufficiently small (even if $\rho>1$ ), then $y_{s}^{*}>\rho \cdot x_{s}^{*}$, also satisfying the incentive-compatibility constraints of the Social Planner's problem.

We see that for low enough $\rho$, the incentive compatibility constraints do not bind. Thus, the optimal contract is revealing, that is, the allocation to the impatient depositors is contingent upon the state. ${ }^{13}$ This result agrees with the standard Diamond-Dybvig model in that the firstbest solution is obtainable as the unique equilibrium when the bank has the option of using

\footnotetext{
${ }^{13}$ This contingent contract can be thought of as a partial suspension of payments. This would then agree with Wallace [1988] who said that the partial suspension scheme works best. In the Wallace model, the bad state of the world occurs when there were more impatient depositors. Thus, a partial suspension occurred when the expected number of impatient depositors increased.
} 
either a suspension scheme (as in this paper) or deposit insurance (as in Diamond-Dybvig). ${ }^{14}$

\section{When Incentive Constraints Bind}

Normally, since private information exists for both types of depositors, we must consider incentive constraints for both types. However, the incentives for the impatient depositors are such that they will always want to report truthfully. Lying would only result in them obtaining a good that they did not desire. The same is not true for the patient depositors. If too much is offered to impatient depositors, patient depositors will be inclined to lie and try to withdraw early.

If the optimal full-information contract did not violate the patient depositors' incentive constraints, then the bank need not consider a non-revealing contract in order to hide information; whether the depositors knew the state of the banks investments would be irrelevant. It is only when the incentive-compatibility constraints are binding (or equivalently, the full-information contract violates the incentive constraints) that the banks' decision to offer contingent contracts becomes important. We now see that such a situation may occur with any utility function (satisfying our assumptions on utility) for certain parameters.

Lemma 2. Under Assumption 1, there exist parameters $\rho, R_{l}$, and $R_{h}$ such that $R_{h}>R_{l}>\rho>$ $y_{h}^{*}$ and under such conditions, the full-information allocation violates the incentive constraints.

When the full-information contract violates incentive constraints, the Social Planner must choose between offering the optimal revealing contract or the optimal non-revealing contract. Given that the full-information contract violates the incentive constraints, it must be that the optimal revealing contract has binding incentive constraints. It is not necessarily the case that the optimal non-revealing contract has binding incentive constraints. We now show that under certain assumptions incentive constraints do indeed bind.

Lemma 3. If utility is $\operatorname{CRRA}\left(u(c)=\frac{c^{1-\alpha}}{1-\alpha}\right), \alpha>1$ (Assumption 1) and $\rho>R_{h}^{1 / \alpha}$, then both the optimal non-revealing and optimal revealing contracts have binding incentive constraints.

Now that we have a set of conditions where both types of contracts have binding constraints, we obtain the following two lemmas that describe properties of each optimal contract which allows us to compare the two in Theorem 2.

\footnotetext{
${ }^{14}$ De Nicolo [1996] shows the first-best is almost achievable with a priority of claims provision.
} 
Lemma 4. When constraints bind, the expected utility of the optimal revealing contract is linear in $\mu$.

Lemma 5. When utility is CRRA and incentive constraints are binding, the expected utility of the optimal non-revealing contract is

(i) increasing and concave in $\mu$ when the relative risk aversion is between 1 and 2

(ii) increasing and convex in $\mu$ when relative risk aversion is greater than 2.

Theorem 2. If utility is CRRA and $\rho>R_{h}^{\frac{1}{\alpha}}$, then a non-revealing contract will be offered when the relative risk aversion is between 1 and 2, and a revealing contract will be offered when the relative risk aversion is greater than 2.

Proof: (See Figure 1.) To show this, first notice that when $\mu$ is either 1 or 0 both contracts provide the same expected utility since the state of nature is known with certainty. From Lemma 4, the expected utility of the revealing contract is linear in $\mu$. This implies that when the non-revealing contract is concave in $\mu$ it is preferred to the revealing contract, and when the non-revealing contract is convex in $\mu$ the revealing contract is preferred. Lemmas 3 and 4 show that the conditions of this theorem cause the respective concavity requirements to be satisfied.

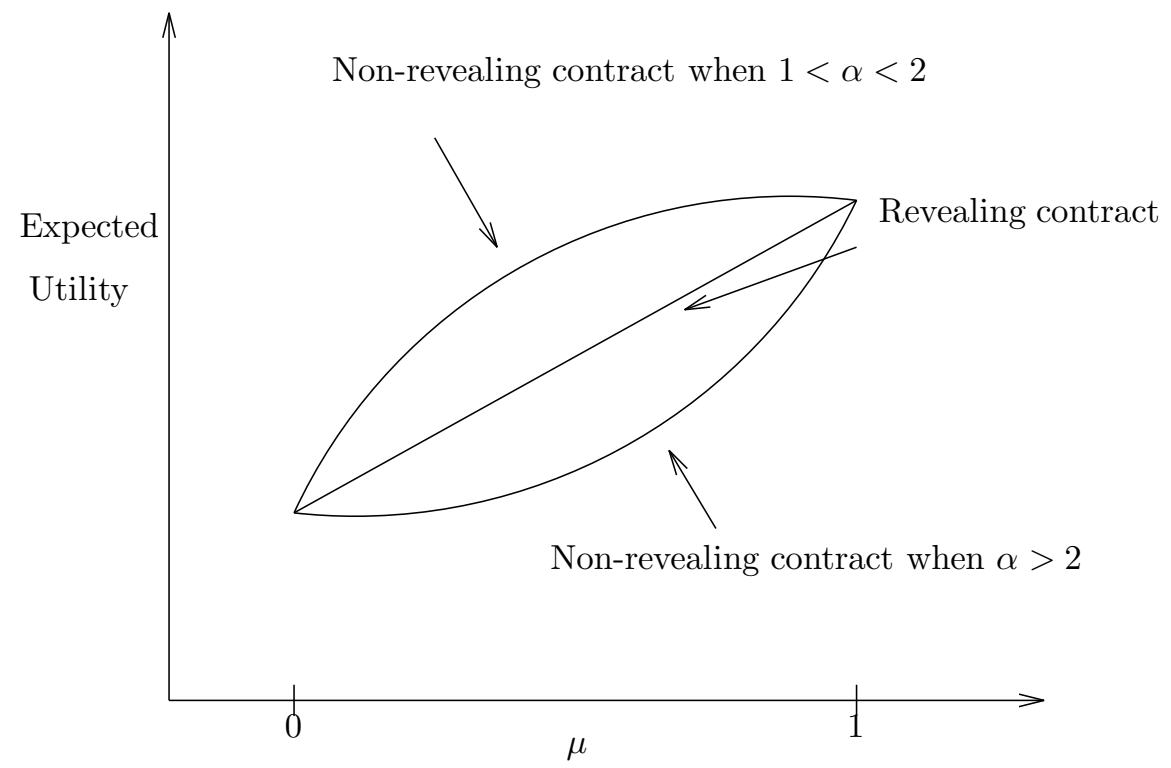

Figure 1: Graph of Expected Utility vs $\mu$. 
From Theorem 2 we see that when relative risk aversion is between one and two, a bank prefers to offer a non-revealing contract. ${ }^{15}$ Such a contract would not be feasible if banks were forced to reveal the state of their investments. Thus laws forcing a bank to reveal such information may be detrimental.

Some intuition as to why this is the case can be gained by looking at the costs and benefits of the non-revealing contract versus the revealing contract. The benefits of a non-revealing contract are that there is more risk sharing against the risk of being impatient than in a revealing contract; the patient depositors are more willing to wait when there is a low return since they believe there is a chance of a high return. However, the cost of a non-revealing contract is that the patient depositors bear all the risk of the investment technology, whereas in a revealing contract they share some of that risk. ${ }^{16}$ Thus, if depositors are moderately risk-averse this risk is not too costly. On the other hand, if the depositors are very risk-averse, the large difference of the payments in the last period are outweighed by the increased risk sharing against the risk of being impatient.

\section{Conclusion}

This paper presented a model in which banks have private information about the return on their assets. If the bank agrees to a contingent contract, then the depositors learn this information. Once depositors learn this information, it is more difficult to prevent patient depositors from pretending to be impatient. We find that instead a bank may agree only to a non-contingent contract in order to keep it information secret. Since the bank sometimes chooses not to reveal its information, we can conclude that there is a potential danger to regulation requiring this information to be made public.

We may ask how robust are the results to environmental assumptions. For instance, we assume that the depositors cannot learn the state of the investments from another bank. If these were relaxed, then it would introduce the possibility of multiple equilibria where banks have trouble coordinating on keeping information secret. If one bank wrote a revealing contract, then it would be best for all others to follow. If all banks wrote a non-revealing contract,

\footnotetext{
${ }^{15}$ In a different framework, Eckwet and Zilcha [1999] show that for higher relative risk aversion (greater than $0.5)$ more information is worse as opposed to the middle range in our model.

${ }^{16}$ In autarky, the patient depositor bears all the burden of the risk of the technology and the impatient depositor bears all the burden of being impatient.
} 
then it would be best for each bank to continue to offer a non-revealing contract. Still, since the possibility of a non-revealing equilibrium exists, the primary conclusion would still hold. Another possible alteration could be the introduction of independent returns for each bank. In order to obtain similar results, we would need another assumption that would prevent depositors from fully diversifying their deposits. Finally, adding a cost to disclosure would only further support our primary conclusion. This cost would increase the relative value of the non-contingent contract expanding the region where non-contingent contracts are preferred and increasing the loss from revealing information in such regions.

Another interesting point worth mentioning is that, in the non-revealing equilibrium, there is a danger of information being revealed. Such revelation can lead to information-based bank runs, since incentive constraints would still be violated. Similar to what happened with Orange County California (see Jorion [1995]), problems are created when there is a low return on investments, but these problems are made worse when they are made public. Impatient depositors such as schools (as opposed to retirement funds) are made much worse off since suspensions or rationing funds are needed. If such information was accidentally released very rarely (say with an exogenous small probability), the non-revealing would still be optimal for a bank. This would lead us to a model with the result that information-based runs can be avoided but the cost of avoiding them is too great (as in Alonso [1996]).

This paper also expands the idea that more information could be worse. It both puts the idea into the framework of banking and introduces a new angle from the better-known insurance example. Rather than discovering who is patient versus impatient in the first period (which would break down the insurance market against being impatient), the discovery of a lower than expected returns to investment in the middle period will increase the patient depositors' desire to pretend to be impatient.

\section{References}

Adao, B., and T. Temzelides (1998): "Sequential Equilibrium and Competition in a Diamond-Dybvig Banking Model," Review of Economic Dynamics, 1, 859-877.

Alonso, I. (1996): "On Avoiding Bank Runs," Journal of Monetary Economics, 37, 73-87. 
Diamond, D., and P. Dybvig (1983): "Bank Runs, Deposit Insurance, and Liquidity," Journal of Political Economy, 91(3), 401-419.

Eckwert, B., and I. Zilcha (1999): "Incomplete Risk Sharing Arrangements and the Value of Information," Foerder Institute Working Paper No. 13-99, Tel Aviv University.

Gorton, G. (1985): "Bank Suspension of Convertibility," Journal of Monetary Economics, 15, 177-193.

HAzlett, D. (1997): "Deposit Insurance and Regulation in a Diamond-Dybvig Banking Model with a Risky Technology," Economic Theory, 9, 453-470.

Hirshleifer, J. (1971): "The Private and Social Value of Information and the Reward to Incentive Activity," American Economic Review, 61, 561-574.

Jacklin, C. J., and S. Bhattacharya (1988): "Distinguishing Panics and Information-Based Bank Runs: Welfare and Policy Implications," Journal of Political Economy, 96(3), 568-592.

Jorion, P. (1995): Big Bets Gone Bad. Academic Press, San Diego.

Kaplan, T. (1996): "Banking, Information, and Circulating Debt.," Ph.D. Thesis, University of Minnesota.

Kaplan, T., and S. Zamir (2000): "The Strategic Use of Seller Information in Private-Value Auctions," Working Paper 221, Center for Rationality, Hebrew University.

Maskin, E., and J. Tirole (1990): "The Principle-Agent Relationship with an Informed Principal: The Case of Private Values," Econometrica, 58(2).

(1992): "The Principle-Agent Relationship with an Informed Principal (II): Common Values," Econometrica, 60(1).

Nicolo, G. D. (1996): "Run-Proof Banking without Suspension or Deposit Insurance," Journal of Monetary Economics, 38, 377-390.

Rothschild, M., and J. Stiglitz (1976): "Equilibrium in Competitive Insurance Markets," Quarterly Journal of Economics, 90, 629-649.

SchleE, E. (2000): "The Value of Information in Efficient Risk Sharing Arrangements," manuscript, Department of Economics, Arizona State University. 
Townsend, R. M. (1988): "Information Constrained Insurance: The Revelation Principle Extended," Journal of Monetary Economics, 21, 411-450.

VerrecchiA, R. E. (1982): "The Use of Mathematical Models in Financial Accounting," Journal of Accounting Research, 20(Supplement).

Wallace, N. (1988): "Another Attempt to Explain an Illiquid Banking System: The Diamond and Dybvig Model with Sequential Service Taken Seriously," Federal Reserve Bank of Minneapolis Quarterly Review, (Fall).

(1990): "A Banking Model in Which Partial Suspension is Best," Federal Reserve Bank of Minneapolis Quarterly Review, (Fall).

\section{A Appendix}

\section{Proof of Lemma 1.}

The Social Planner's problem implies that the optimal contract will separate the impatient from the patient and prevent the possibility of a bank run. Furthermore, impatient depositors will only withdraw at time 1 , while patient depositors will only withdraw at time 2 .

There are several steps necessary to reduce the problem to this form.

1. The contract would result in at least some patient depositors withdrawing at time 2 .

Proof by contradiction. Suppose that all patient depositors withdraw at time 1. The best contract in this case causes all depositors to withdraw at time 1 and receive one unit of time 1 good. A strict improvement is $x_{s}=1, y_{s}=R_{l}$, and $F=.5$. Such a contract separates patient and impatient depositors and is always feasible. Therefore, at least some patient depositors withdraw at time 2 .

2. The contract offered will cause the impatient depositors to withdraw at time period 1 . Impatient depositors only value time 1 goods. The only reason for them to withdraw at time 2 , would be indifference, i.e., if the time 1 offer were zero. If the time 2 payment were greater than zero, it would be an improvement for the planner to offer an amount that was close to zero to the time 1 withdrawers. This would cause the impatient to withdraw at time 1 and receive nonzero payment as opposed to receiving no utility from a time 2 
withdraw. The savings from not having to pay impatient depositors any time 2 goods could be distributed to time 2 withdrawers, all of whom will be patient. We know that more than zero would be offered at time 2 otherwise some patient depositors might not wait until time 2 violating the results of the previous step.

3. The contract offered will not pool or partially pool impatient and patient depositors together.

There are two types of pooling contracts. Type 1 has both types withdrawing at time 1 . Type 2 has both types withdrawing at time 2 . These types can be ruled out by steps 1 and 2 , respectively. Partial pooling occurs when either some of the patient depositors withdraw at time 1 or some of the impatient depositors withdraw at time 2. By the previous step, all impatient depositors withdraw at time 1 . Therefore the only case left is having some patient depositors withdraw at time 1. This can only occur if $E\left[u\left(y_{s}(f)\right) \mid x_{s}\right] \leq u\left(\rho \cdot x_{s}\right)$. If this held with equality, an improvement would be to raise $y_{s}(f)$ by a small amount causing the patient depositors to wait and pay for it by the returns on the foregone time 1 goods, which would be greater than $\rho$. Therefore $E\left[u\left(y_{s}(f)\right) \mid x_{s}\right]<u\left(\rho \cdot x_{s}\right)$. By step 1, there exists at least some patient depositors waiting so $E\left[u\left(y_{s}(f)\right) \mid x_{s}\right] \geq u\left(\rho \cdot x_{s}\right)$. This is a contraction, which implies no partial pooling can occur.

4. The contract offered will be separating and prevent the possibility of a bank run.

Since a contract is not pooling or partially pooling by step 3, it must be separating. A speculative bank run of the Diamond-Dybvig type occurs if everybody believes everybody else is going to withdraw early or at least a large number of patient depositors are going to withdraw early. A bank run occurs because $y(f)<y\left(\frac{1}{2}\right)$ for some $f$ greater than $\frac{1}{2}$. This can be prevented by keeping $y(f)$ constant when $f$ is greater than $\frac{1}{2}$. By setting $F=\frac{1}{2}$, we can feasibly do this.

\section{Proof of Property 1.}

The solution to the full information problem has only feasibility constraints. The first-order conditions are

$$
R_{s} u^{\prime}\left(y_{s}^{*}\right)=u^{\prime}\left(x_{s}^{*}\right)
$$


By substituting feasibility into the first order condition, we find

$$
R_{s} u^{\prime}\left(y_{s}^{*}\right)=u^{\prime}\left(2-y_{s}^{*} / R_{s}\right)
$$

Notice that equations 8 (one for each state $s$ ) and the two feasibility conditions are enough to provide a solution. None of the equations contains $\mu$.

\section{Proof of Property 2.}

The proof is by contradiction. Assume $y_{h}^{*} \leq y_{l}^{*}$. Since the utility function $u$ is concave $\left(u^{\prime}\right.$ is decreasing), $u^{\prime}\left(y_{h}^{*}\right) \geq u^{\prime}\left(y_{l}^{*}\right)$. In addition since $R_{h}>R_{l}$, we have $R_{h} \cdot u^{\prime}\left(y_{h}^{*}\right)>R_{l} \cdot u^{\prime}\left(y_{l}^{*}\right)$. This shows that given our assumption the LHS of equations 8 are higher for the high state than the low state. Now let us look at the RHS, $u^{\prime}\left(2-y_{s}^{*} / R_{s}\right)$. Since $y_{h}^{*} \leq y_{l}^{*}$ and $R_{h}>R_{l}$, we have $y_{h}^{*} / R_{h}<y_{l}^{*} / R_{l}$. This implies $u^{\prime}\left(2-y_{h}^{*} / R_{h}\right)<u^{\prime}\left(2-y_{l}^{*} / R_{l}\right)$. Thus, given our assumption the RHS is lower for the high state than the low state. This contradicts that the first-order condition, $R_{s} u^{\prime}\left(y_{s}^{*}\right)=u^{\prime}\left(2-y_{s}^{*} / R_{s}\right)$, holds for both states. Therefore, $y_{h}^{*}>y_{l}^{*}$.

\section{Proof of Property 3.}

In all states of the world, the return to investment $R_{s}$ is strictly greater than one. This and equations 7 imply that $u^{\prime}\left(y_{s}^{*}\right)<u^{\prime}\left(x_{s}^{*}\right)$. Since $u$ is concave, $u^{\prime}$ is decreasing. Therefore, $y_{s}^{*}>x_{s}^{*}$.

\section{Proof of Property 4.}

We can use equations 8 to compute comparative statics on $x_{s}^{*}$ and $R_{s}$. Differentiating them equation with respect to $R_{s}$ gives us

$$
d R_{s} u^{\prime}\left(R_{s}(2-x)\right)-R_{s} u^{\prime \prime}\left(R_{s}(2-x)\right)\left(R_{s} d x+(2-x) d R_{s}\right)=u^{\prime \prime}(x) d x
$$

We can now use this equation to solve for $d x / d R_{s}$,

$$
\frac{d x_{s}^{*}}{d R_{s}}=\frac{u^{\prime}\left(R_{s}(2-x)\right)+R_{s}(2-x) u^{\prime \prime}\left(R_{s}(2-x)\right)}{R_{s}^{2} u^{\prime \prime}\left(R_{s}(2-x)\right)+u^{\prime \prime}(x)} .
$$

Since $u$ is concave, the denominator is negative. Under Assumption 1 (A1), the numerator is negative, while under Assumption 2 (A2), the numerator is positive. These results imply that 
$d x / d R_{s}$ is positive under A1 and negative under A2. Since $R_{h}>R_{l}$, we have $x_{h}^{*}>x_{l}^{*}$ under A1 and $x_{h}^{*}<x_{l}^{*}$ under $\mathrm{A} 2$.

We can further show that if returns, $R_{s}$, were one, then by the first order conditions $x$ must satisfy $u^{\prime}\left(2-x_{s}^{*}\right)=u^{\prime}\left(x_{s}^{*}\right)$. This equation implies $x_{s}^{*}=1$. Making further use of our comparative statics ( $\operatorname{sign}$ of $d x / d R_{s}$ ), the inequality of $R_{l}>1$ implies that $x_{l}^{*}>1$ under A1 and $x_{l}^{*}<1$ under A2. Thus, completing the proof. $\square$

\section{Proof of Lemma 2.}

By Properties 1 and 2, the full information contract $\left\{x_{s}^{*}, y_{s}^{*}\right\}$ is such that $y_{h}^{*}>y_{l}^{*}$ and $x_{h}^{*}>x_{l}^{*}>$ 1. Since $x_{h}^{*}>1$, there is risk-sharing and feasibility requires that $R_{h}>y_{h}^{*}$. Thus, it is possible to choose an $\rho$ and $R_{l}$ for each $R_{h}$ such that $R_{h}>R_{l}>\rho>y_{h}^{*}$.

From Property $1\left(y_{h}^{*}>y_{l}^{*}\right)$, we have $\rho>y_{s}^{*}$. From Property $2\left(x_{s}^{*}>1\right)$, we have $\rho \cdot x_{s}^{*}>\rho>$ $y_{s}^{*}$. Thus $u\left(y_{s}^{*}\right)<u\left(\rho \cdot x_{s}^{*}\right)$, violating the incentive constraints. Therefore, the full-information contract violates the incentive constraints and the solution to the Social Planner's problem will have binding constraints.

\section{Proof of Lemma 3.}

When a contract is revealing and the investment return is high, the amount paid to the impatient depositors $x$ should maximize $(1 / 2)\left[u(x)+u\left(R_{h}(2-x)\right)\right]$. The first-order condition is given by $u^{\prime}(x)=R_{h} u^{\prime}\left(R_{h}(2-x)\right)$. Using the specific form of the utility function and raising each side to the $(\alpha-1) / \alpha$ power, we can rewrite this as $u(x)=R_{h}^{1-(1 / \alpha)} u\left(R_{h}(2-x)\right)$. The incentive constraint is violated if $u\left(R_{h}(2-x)\right)<u(\rho \cdot x)=\rho^{1-\alpha} \cdot u(x)$. This indeed occurs if $\rho>R_{h}^{1 / \alpha}$ since $u$ and $1-\alpha$ are negative. Likewise, the incentive constraint for the return is low is violated whenever $\rho>R_{l}^{1 / \alpha}$. Since $R_{h}>R_{l}$, both are violated when $\rho>R_{h}^{1 / \alpha}$.

When a contract is non-revealing, the amount paid to the impatient depositors $x$ should $\operatorname{maximize}(1 / 2)\left[u(x)+\mu \cdot u\left(R_{h}(2-x)\right)+(1-\mu) \cdot u\left(R_{l}(2-x)\right)\right]$. This can be written as $(1 / 2)[u(x)+$ $u(K(2-x))]$ where $K$ is $\left(\mu R_{h}^{1-\alpha}+(1-\mu) R_{l}^{1-\alpha}\right)^{\frac{1}{1-\alpha}}$. Thus, the incentive constraints will be violated whenever $\rho>K^{\frac{1}{\alpha}}$. Since $K$ is less than $R_{h}$, this is violated when $\rho>R_{h}^{\frac{1}{\alpha}}$. Thus, for both cases the unconstrained optimum will violate the constraints. Since the maximand is concave, the constrained optimal will have binding constraints. 


\section{Proof of Lemma 4.}

Since the revealing incentive constraints are binding (Equation 4 in the Social Planner's problem), the optimal revealing contract, $\left(x_{s}^{r}, y_{s}^{r}\right)$, satisfies $y_{s}^{r}=\rho \cdot x_{s}^{r}$. By substituting into the feasibility constraint $y_{s}^{r}=R_{s}\left(2-x_{s}^{r}\right)$, we get $\rho \cdot x_{s}^{r}=R_{s}\left(2-x_{s}^{r}\right)$. Solving gives us, $x_{s}^{r}=2 R_{s} /\left(\rho+R_{s}\right)$ and $y_{s}^{r}=2 \rho R_{s} /\left(\rho+R_{s}\right)$.

By using these results, the ex-ante expected utility of the revealing contract equals $\frac{1}{2}\left[\mu\left(u\left(2 R_{l} /\left(\rho+R_{l}\right)\right)+\right.\right.$ $\left.\left.u\left(2 \rho R_{l} /\left(\rho+R_{l}\right)\right)\right)+(1-\mu)\left(u\left(2 R_{h} /\left(\rho+R_{h}\right)\right)+u\left(2 \rho R_{h} /\left(\rho+R_{h}\right)\right)\right)\right]$. This is of the form $\mu \cdot$ const $_{1}+$ $(1-\mu) \cdot$ const $_{2}$, which is linear in $\mu$.

\section{Proof of Lemma 5.}

This Lemma is proved by looking at the first and second derivatives of the objective function with respect to $\mu$. The non-revealing contract, $\left\{x_{s}^{n r}, y_{s}^{n r}\right\}$, has the property that $x_{l}^{n r}=x_{h}^{n r}:=x^{n r}$. Now notice that there are two feasibility constraints and one IC constraint with three unknowns: $x^{n r}, y_{l}^{n r}$, and $y_{h}^{n r}$. Thus, we can use these constraints to solve for the contract directly. By combining these, we arrive at

$$
u\left(\rho x^{n r}\right)=(1-\mu) \cdot u\left(R_{l}\left(2-x^{n r}\right)+\mu \cdot u\left(R_{h}\left(2-x^{n r}\right)\right)\right.
$$

By using the specific form of the utility function $\left(u(c)=\frac{c^{1-\alpha}}{1-\alpha}\right)$, we find that $x^{n r}$ equals $2 K(\mu) /(\rho+K(\mu))$ where $K(\mu)$ is $\left((1-\mu) R_{l}^{1-\alpha}+\mu R_{h}^{1-\alpha}\right)^{1 /(1-\alpha)}$.

Therefore, the expected utility of the non-revealing contract equals

$$
\begin{gathered}
E U^{n r}=\frac{1}{2}\left[(1-\mu)\left(u\left(y_{l}^{n r}\right)+u\left(x^{n r}\right)\right)+\mu\left(u\left(y_{h}^{n r}\right)+u\left(x^{n r}\right)\right)\right]= \\
\frac{1}{2(1-\alpha)}\left[\rho^{1-\alpha}+1\right]\left(\frac{2 K(\mu)}{\rho+K(\mu)}\right)^{1-\alpha}
\end{gathered}
$$

For simplicity, denote $K_{2}$ as $\frac{1}{2}\left[(2 R)^{1-\alpha}+2^{1-\alpha}\right]$. We find that $d E U^{n r} / d \mu$ equals $\rho K_{2} K^{-\alpha} K^{\prime} \cdot(K+\rho)^{\alpha-2}$. The value of $K^{\prime}$ is $K^{\alpha}\left(R_{h}^{1-\alpha}-R_{l}^{1-\alpha}\right) /(1-\alpha)$. Since $(1-\alpha)$ and $\left(R_{h}^{1-\alpha}-R_{l}^{1-\alpha}\right)$ are of the same sign, $K^{\prime}$ is positive. Since $\rho, K_{2}$, and $K$ are also positive, $E U^{n r}$ is increasing in $\mu$.

For simplicity, denote $K_{3}$ as $\left(R_{h}^{1-\alpha}-R_{l}^{1-\alpha}\right) /(1-\alpha)$. We find that the second derivative, $d^{2} E U^{n r} / d \mu^{2}$, is equal to $\rho K_{2} K_{3}(\alpha-2)(K+\rho)^{\alpha-3} K^{\prime}=\rho K^{a} K_{2} K_{3}^{2}(\alpha-2)$. The values $\rho, K, K_{2}$, and $K_{3}$ are all positive. Therefore, the sign of the second derivative is the same sign as $(\alpha-2)$. This means it is concave when $\alpha<2$ and convex when $\alpha>2$. 